http://dx.doi.org/10.4314/ejotmas.v7i1-2.23

\title{
COMMUNITY RADIO: AN INSTRUMENT FOR GOOD GOVERNANCE IN NIGERIA
}

\author{
*'Rantimi Jays JULIUS-ADEOYE, Ph.D.
}

\begin{abstract}
Decree No. 38 of 1992 enacted under the administration of General Ibrahim B. Babangida put a stop to fifty seven years of government's exclusive ownership and operation of broadcasting in Nigeria. However, with the cost of setting-up, management and obtaining license for media station being prohibitively expensive, the system can only be accessed by the rich and powerful in the society, thereby depriving rural communities' involvement in the development of the country. As part of the panoply of strategies to ensure rural communities' participation in democratic governance, there is need for the establishment of rural community radio stations, which is very much different from educational institutions' type currently being paraded as community radios but rather a training room for communication and theatre arts students. Using historical-analytic method, this article looks at the role community radio could play in making good governance in Nigeria accessible to every segment of society, especially the rural populace. Therefore, it is recommended that Nigerian Broadcasting Commission (NBC) policy should consider the inclusion of community radio as the third in the sector of radio broadcasting in Nigeria after public and commercial ownership. Furthermore, since community radio is essentially non-for-profit, government should make the operation licence free or at a minimal cost to the host community.
\end{abstract}

Keywords: Community radio, NBC, Good governance, People's participation, Nigeria

\section{Introduction}

Media provide the information needed to run an open and successful government (Omoera 2010). As the role of every government is to provide good governance to its people, it is crucial for every segment of society to have access to state programmes and policies. This is

*'Rantimi Jays JULIUS-ADEOYE, Ph.D. is of the Department of Theatre and Film Studies, Redeemer's University (RUN), Ede, Nigeria

Email: julius.rantimi@gmail.com 
because participation of more people in the process of governance provides effective opportunity for the nation's development. For instance, government programmes and policies will be adequately disseminated in order to create the good governance desired by the people. Good governance is about having an all-inclusive participation in the process that enhances good living condition by the generality of the people and not by a selected few in the society. According to Zakaria (2010), "good governance entails the principles of transparency, accountability and participation." His position is not different from that of Bazlur (2009) who believes that in good governance system there exists many opportunities for the peoples' participation. He presents good governance in three stages: (a) good political governance; (b) good social governance; and (c) good economic governance. In order to make for a clear understanding of the system, Bazlur (2009) describes each stage, thus:

(A) Good political governance: In good political governance, there exists decentralization of power and administrative authority and transparency; people's participation and accountability exist in every stage of governance. Besides, establishment of justice and creating speedy trial exist in the boundary of good political governance.

(B) Good social governance: In good social governance there exists building strong civil society, establishing human rights, equality of both male and female, exchanging information especially to ensure [peaceful coexistence] in urban and rural areas and making it easier, to encourage the businessmen to spend a little portion of their income in social welfare.

(C) Good economic governance: In good economic governance there exists some points such as, to enhance the amount of budget necessarily regarding social development; to reform tax management, to make the information available regarding credit and government services and to ensure the access of poor community to these services; to take appropriate decisions by reviewing the impacts of trade policy of multinational companies and world trade upon the poor community people.

\section{Community Radio and Rural Society}

Since media refer to every organ of mass communication, it is expedient to limit my discussion to rural community radio, a type of radio whose role is to help make information available to people who reside in areas where accessibility to primary media is not easily available. The importance of community radio cannot be over-emphasized in a society 
that practices democratic government. Therefore, the fact that community radio has a vital role to play in the sensitization of rural dwellers in the participation of good governance in Nigeria and elsewhere all over the world is no longer news, but in what area can the medium function from one society to the other? Vital areas in which the medium can effectively function include sensitization, development and harnessing grassroots participation in government.

According to Section 22 of Nigeria's 1999 Constitution, "The press, radio, television and other agencies of the media shall at all times be free to uphold the responsibility and accountability of the government to the people." This means that the constitution recognizes the primal role of radio in adequately informing the people about what the government promised to do and what it is doing. It must be emphasized that radio is a very powerful tool in changing people's opinion on societal issues. For example, Agbowo and Orogun communities in Ibadan, Oyo State, Nigeria, experienced floods from 2004 to 2005 due to the attitude of dumping refuse into the canal and drainage by the inhabitants during rainy season. In 2005, the Oyo State government utilized Broadcasting Corporation of Oyo State (BCOS) Radio Station to run series of campaign against the attitude of dropping refuse in canal and blocking the free flow of water. The campaigns also highlighted other problems that blocked drainage can create in the community. The campaign impacted positively on the people of Agbowo and Orogun communities who desisted from the act and also constituted themselves into a form of taskforce to prevent those who might want to drop refuse into the canal and drainage. This writer lived in Agbowo at the time of the event as a postgraduate student of the University of Ibadan and witnessed how radio was used to change the people's opinion and perspective. Because radio is the most popular medium for passing information to people in the communities no matter how remote or removed from urban development, it is important to use the medium to promote issues such as the evil of corruption in government, government policies, peoples' right, ethnic tolerance, among other things that could impede or act as catalyst to the development of society.

Food Agriculture Organization (FAO) writes that media, of which community radio (inclusive of community radio), "is an important tool for the rapid diffusion of important messages on new agricultural production ideas and techniques as well as on health, nutrition, family planning and other social and cultural issues" (1999). Since radio as a broadcast medium helps to form opinion on products and services as well as influence "people's attitude and behaviour" (Sanders and Goddard, 2002), rural community radio would be effective in helping 
to educate the people of a locality on attitude towards vandalism and outright stealing of government facilities and installations. For example, campaigning about the problem and danger associated with vandalism of petroleum pipes, stealing of electricity cables and so on which are common features in Nigerian rural communities, on rural community radio it will most likely persuade the people to be the keeper of such materials because they will know that it is to their own advantage to take care of such property.

The emergence of commercial radio broadcasting makes communication to be a tool in the hands of the rich and powerful in the society to the detriment of the poor and the masses. As a result, participation in decision-making on how they want to be governed becomes more difficult. Mahmud (2006) captures it thus:

Global media has become the powerful tool to control over people and has been grown as a profit sector where people's voices are quite marginalized and neglected. The nature of communication is changing that is keeping impact over life and livelihood. The role of controlled media is dominating the world where common people have least of the access to take part in decision-making process expressing their views and opinion and also they are left out from the development process.

Many governments in the developing nations of which Nigeria is one, unconsciously collude with the rich and powerful in the society to further disenfranchise the masses by making radio stations too expensive to establish. The humongous amount required to set-up a radio station coupled with lack of government's support is not helping matters. According to Mahmud (2006), community radio is a prior agenda that can help building up participatory practice in the society, which leads to people's governance. It can facilitate people's access and promote their participation in local level decision-making process, which ultimately results in participatory governance in the society. We can say community radio can play the role as promoter of participatory, accountable and transparent governance system in a society and it can also create enormous opportunities for growth and poverty reduction.

Based on the above, the Nigerian government needs to put in place a framework that will allow for easy establishment, operation and participation of rural community radio in the broadcast space of the country. The government ought to allow, and if need be help 
communities, agencies and non-governmental organisations who are poised to serve the society without profit to set-up a community radio station. Bazlur (2006) claims that community radio "can work as a catalyst with the government, opposition party, administration, businessmen, and civil society leaders for keeping democratic process uninterrupted, and as an aftermath, both sides become positively influenced."

One area in which community radio can enhance good governance is in sensitizing the rural population on the importance of participating in the process of democracy (Omoera, 2006). For instance, before and during the Nigeria's general election of 2007, both the Federal Radio Corporation of Nigeria (FRCN) and Nigeria Television Authority (NTA) helped to sensitize the people through programmes such as "Nigeria Decides". It must be noted that from the title of the programme, it is discernible that the language of presentation is English. Sadly, a majority of Nigerians in rural community who are largely non-literate cannot comprehend English. Ajibade and Alabi (2017) argue that "since the advent of broadcasting in Nigeria, it has remained entirely an urban affair. Almost all the radio stations are located in urban areas; they cater for the needs and interest of the urban dwellers in their programming" (28). In view of the fact that the society is the 'consumer' of government programmes and policies, it is important to emplace an all-inclusive communication medium that will allow the masses process and debate whatever they are going to 'consume,' thereby ensuring people's participation in governance.

\section{Community Radio and Good Governance}

Different scholars have propounded many definitions of community radio, with an underlying and acceptable fact that community radio is the most effective broadcast system which allows the involvement of community members in broadcasting and opinion formulation. According to Thomson (1998), community radio is a "radio broadcast in a specific locality, whose editorial trust reflects the news interest of that environment and the airwave distribution is limited to the locality" (p.28). In spite of the fact that Thompson's definition did not mention the language of broadcast and the entertainment part of the medium, it captures to a great extent the people who community radio seeks to serve. In the words of Jayaweera (2009), the common features of community radio are:

1. Community radio is constituted as a non-for-profit (not for loss) operation. 
2. It is intended to serve specific communities, either geographicallybased or communities of interest.

3. It has a management structure that is representative of the community that the station is designed to serve and to which it should therefore be accountable.

4. It provides programming that is relevant to the community being served, with emphasis on local content and community empowerment.

5. Community radio actively involves community members in its operations- both as audience members and as participants.

The import of the features above is that, community radio has the function of making the people part of the government of the day and participants in their community development. Good governance entails making government programmes serve the need of the people that it is designed for and for the people to understand that they are involved in decision-making which impacts on their well-being and development. In this regard, one important way to have the people in the grassroots effectively participate in government, community development, group and individual empowerment is through necessary information provided by community radio that serves their own needs. Al-hassan, Andani and Abdul-Malik (2011) explain that community radio is a type of radio service that offers a model of radio broadcasting beyond commercial and public service. Community radio broadcasting serves geographic communities and communities' interest. The content of broadcasting is largely popular and relevant to a local/specific audience but which may often be overlooked by commercial or massmedia broadcasters. Community radio stations are operated, owned, and driven by the communities they serve. Community radio is not-for profit and provides a mechanism for facilitating individuals, groups, and communities to tell their own diverse stories, to share experiences, and in a media rich world to become active creators and contributors of media.

Community radio provides the marginalized rural and poor people an opportunity to discuss issues and government policies as they affect them. For example, in Nigeria, there are ecological problems, communal conflicts, lack of basic amenities such as good road, hospital, recreational facilities and so on. While there is rapid government response in the urban areas in most instances whenever any of these occurs, there is always little, slow or no response in the rural communities. Adequate communication with the people will reduce the risks associated with such problems and lack. For example, "Abule Oloke Merin" and "One Thing at a Time" were two popular radio dramas 
in early 2000s that helped to educate Nigerians about how the HIVI AIDS pandemic and other health related issues in the society. The dramas were presented on Radio Nigeria and Ogun State Broadcasting Corporation (OGBC) radio in English and Yoruba respectively. Other impactful examples abound in radio dramas sponsored by the Society for Family Health (SFH) across the country such as "Odenjiji (Igbo), Geri Muna Fada (Hausa) ... radio magazine programmes aired twice weekly across radio stations in the 36 states and FCT" (Uka, 2017). This is probably so because people in remote rural communities often cannot receive the radio reception of many urban-based stations, a shortcoming that community radio will readily surmount. Moreover, there are many other communities in the South western part of the country whose dialect of Yoruba is markedly different from the one used for the drama. Based on research conducted in many countries where community radio practice is in operation there has been recorded improvement on awareness and knowledge of solutions to community development problems within various sectors including culture, rural development, education, hygiene and sanitation, agriculture and local governance among rural people living in the areas covered by the broadcast.

In Ghana, for example, where community radio has been established, it is believed that "it provides voice to the voiceless and allows rural communities to play active role in their development" (Obeng, 2010). As a theatre for development (TfD) practitioner who worked with rural communities on some developmental projects, it is discovered that many people living in rural communities will work to provide for themselves needed amenities without the support of the government if they have adequate information on how to go about it. This is because in some of these communities the people want to provide for themselves and their community needed amenities such as bore-hole in order to get good drinking water, public toilet, community hall, etc., but without the required knowledge of how to make these happen without government support. As diseases and natural disasters are common features in many developing nations, community radio becomes a ready tool that the people can use in managing the crises, and to avoid a recurrence of some of them.

It must be noted that since the Federal Government of Nigeria's intention for creating local government councils is to bring good governance to the people at the grassroots, therefore, it is important to have the rural dwellers participate in the process of governance, especially within their own communities. In this regard, they can adequately capture radio contents that will address their developmental needs. Having a rural community radio in their localities will enable them a direct discussion with would-be council leaders during election 
period. Election candidates may also participate in programmes that can be monitored by the electorates in the communities that they are aiming to represent no matter how remote. This process will enable rural electorate inform the candidate on what is lacking in the community and things they want done for them.

Apart from the issues of election, basic health, human rights violation, "poverty, agriculture, gender inequality, education, social problems, among others, could be the focus for programming" (FAO, 1999) on community radios in the rural areas. When the people are directly involved in the decision-making, there is bound to be a change for the better. Owing to the ownership of radio by its host community or community agencies, its decision-making and programme output will be accessible to the people. Other areas where community radio will serve as effective tool in rural and community broadcasting are in making new laws passed by the National Assembly known by the people, especially the non-literate members of the society. For example, it will enhance good governance in areas of national orientation, and in educating women and children about their rights in the nation's constitution and other laws enacted by both the states' and national assemblies.

\section{Government Policies and Community Ownership of Radio Station in Nigeria}

As mention earlier, Nigeria's 1999 Constitution provides for the freedom of the media which includes radio broadcast. Therefore, community ownership of radio station is in one way or the other covered by the constitution. The overall aim of any community radio is to promote integrated rural development that will create an enabling environment for government and the rural populace interaction in order to achieve development. When this aim is achieved the people can then say they have dividends of good governance. In a nutshell, achieving good governance and all inclusive participation in democratic process is not possible without community, civic representatives and government collaboration. So, creating avenue for adequate dialogue between the three through talk shows, discussion and magazine programmes on community radio is highly essential.

The Nigerian Broadcasting Commission (NBC) is the regulatory agency set up by the government to receive, process, and issue application and licence for any individual, community, agencies and non-governmental organisations that want to operate community radio. Since community radio is a non-for-profit broadcast medium whose sole aim is to serve as medium for discussions that will bring about community development it is difficult to remain in operation without governmental and philanthropic support. So, requesting for very high 
licence fees is inimical to the development of the medium. For example, the NBC, which is the licensing body makes a demand of N10 million (US\$32, 787.00 at the official exchange rate of N305 to $\$ 1$ ) for community radio broadcast recognized by the same body as non-forprofit. Apart from the licence which must be renewed every five years at the same cost, the station must pay $2.5 \%$ of its annual turnover to the commission. Failure to comply with this regulation will result in the licence withdrawal. This is contrary to what obtains in Mali, a neighbouring West African country. According to Kawu (2008), in Mali, you apply for a community radio licence from the broadcasting regulatory body Conseil Superieur de la Communication (CSC) which check the availability of frequency, by the CSC informing the comite de regulation de telecommunication. If the frequency is available then the radio station is allowed to use it, otherwise a new frequency is allocated. No money is paid to start a station, but each year, a frequency allowance of CFA 10,000 is paid by the station. The democratic way of establishing a radio station in Mali gives the country the "reputation of being the centre of the most diversified experience of radio on the African continent" (Kawu 2008).

While people do not pay money to establish a radio station in Mali, government unnecessary bureaucratic bottleneck in Nigeria hampers community radio establishment. Among these bureaucratic demands is the payment of $\mathrm{A50,000.00}$ for application form. The No.5 of NBC requirement for licensing a community radio station states that: the application is processed by the Commission, recommended to the Board of the Commission, for onward transmission, through the Minister of Information and Communications, to the President. (The President, by constitutional provision has the power to give the final approval for Radio and Television broadcast Licences). As the commission saddled with the responsibility of licensing community radio in Nigeria is still foot-dragging in allowing rural community radio establishment, in South Africa "government plays a major role in the development of community radio. Currently, the government provides infrastructure to $90 \%$ of the community radio stations in the country" (Bolokan, n. d.). However, due to lack of government support, it is difficult for poor communities to participate in the ownership of community radio in Nigeria.

Nevertheless, it must be noted that in Nigeria there exists two types of community radio, namely, campus based community radio and rural community based community radio. While it is a bit easy for educational institutions to set-up and operates a radio station, the reverse is the case with rural settlers who are battling with poverty and other vagaries of life. For clarity's sake, these two types of community radio (campus and rural broadcasting) in Nigeria are 
highlighted in the 2003 revised policy of NBC. Until this revised policy, in the word of Julius-Adeoye (2011), "there is no genuine community radio station in Nigeria, what we have is state and federal governmentowned broadcasting stations in communities." Even in the revised policy, the categorization of campus radio as community radio is confusing. There needs to be a distinction between a community radio and educational institution radio station. This is because NBC has licensed a number of the latter (27 as the time of writing this paper) and people often confuse it with the former just because its operation is within an institution of higher learning and at times to the adjoining communities. In addition, the fact that institutional radio is a noncommercial radio also adds to the confusion. While campus based community radio is wholly owned by academic institution for the purpose of serving as practical and technical training aid to theoretical education in communication and broadcasting, the other is by, for, and of a specific marginalized rural community in order to pursue a participatory social development agenda. The ownership, management and operation of the latter are by the representatives of the community or community development associations (CDA), and it is non partisan, non-sectarian and not-for-profit.

Akingbulu claims that (2009) "rural Nigeria is grossly underserved by existing radio stations. From policy to legislation and regulation, the odds were stacked against giving voice to the marginalised sections of the country." As the people who reside in the adjoining communities of institutional radio cannot be part of the daily running, management and content development of the medium, this means that there is yet to be a community wholly owned radio station in Nigeria. It is understandable that based on the fact that many of the universities in Nigeria are communities in their own right because they have oncampus residency for both staff and students, and any radio station located within such an environment can also be regarded as community radio. However, because these populations are well enlightened and are also served by mainstream broadcast media, a campus based radio should be differentiated from a community radio that serves people in the rural communities mainly.

The higher institutions based radio stations should be seen as laboratories for students training, because this is the way it is conceived by NBC. Julius-Adeoye (2011) observed that as at 2009, eight campus based community radios have commenced operation out of the twentyseven licensed by NBC. The number has since increased, yet there is no single rural community based radio station serving the broadcasting needs of the people. In Nepal for example, after Radio Sagarmatha, the first community radio which Nepal Forum of Environmental Journalists (NEFEJ) assisted to come into existence in 1997, with the 
Community Radio Support Centre (CRSC), the number has risen to more than 100 stations in 2009 (Mainal, Chapagain \& Subba, 2009). Also, this has allowed grassroots participation in the governance process of Nepal. In Nigeria, there has been a concerted effort by individuals and groups such as the Nigeria Community Radio Coalition (NCRC) and Institute for Media and Society (IMS) with support from Panos Institute West Africa (PIWA) and World Association of Community Radio Broadcasters (AMARC), including academic professionals mounting pressure on government to licence community radio. Ajibade and Alabi note that the partnership of these groups "gave birth to Initiative on Building Community Radio in Nigeria" (2017, p.31). As part of the effort to rally support for the establishment of community radio, a conference on community broadcasting was organized at University of Ibadan in 2011 in memory of Professor Alfred Opubor who the federal government had made to head a committee that developed a policy framework for the establishment of community radio station for the country in 2006.

\section{Further Discussion and Conclusion}

As the government set-up organisation such as the Nigerian Broadcasting Commission (NBC) to consider the application, regulate, and licence or withhold licence of individuals and organisations who want to establish a radio station, without the involvement of a neutral organ, it still controls the operation of the medium. So, in order to have a balanced participation in the control of radio operation, there is need for a neutral organization made up of civil society to work alongside that of the government or to serve as check on the excesses of the government body. Although, both the national and states' assemblies have expressed strong support for community radio since 2006 (Akingbulu, 2009), yet more than a decade after that decision, there is no wholly rural community radio in operation. The government will do well to encourage the quick take-off of rural community radio if it drastically reduces the amount required by NBC for the establishment of community radio station.

It is noteworthy to state here that in a democratic society, every individual has the right to information that concerns his or her safety and development no matter where such a person resides in the society. Therefore, community radio has a primal role to play in the development, dissemination and propagation of government policies in rural communities. If it is established in local government areas without interference from the state and politicians, it has the capacity of speeding up government developmental agenda by involving the people in the operation of programmes within their locality. This will serve as a means of encouragement for people within the society to 
enthusiastically participate in the activities that will bring safety and development to their communities. A good example in this regard was witnessed in Nicaragua sometime in August 2012. On that occasion, some women community radio workers during a workshop developed messages for broadcast in order to promote Nicaragua's Law 779 that prohibits violence against women. Their aim, apart from campaigning against violence against women, is to make the rural Nicaragua women aware of the existence of such a law in the country (UNESCO, 2012). This type of campaign programme that is geared towards making rural women aware of the goings-on around them can be done here in Nigeria by the people.

Beginning from 1994 when the first license was issued for independent media broadcast in Nigeria, the list of radio stations has grown to more than thirty private/individual stations which are mainly commercial radios with no single community radio license. Based on this fact, it is important for a separate body to be set up by the government with the contribution of community leaders, civil society organisations and independent media broadcast owners who will see to the governance and operational framework of community radio. There must also be a law or bill to support the new body and protect it from the overt influence of government and politicians. If the national assembly passes it as law it will determine the terms of office of the members. This is unlike the board of commission for the NBC whose appointment is by the nation's president based on the advice of the Minister of Information. The proposed regulatory body's area of operation should not go beyond community radio. For example, in Australia, there is a Community Broadcasting Association (CBAA) which is the national peak body for community radio and television stations in Australia. The CBAA is responsible for sector advocacy and representation, providing services and benefits to members and managing sector wide projects without government involvement. The association makes available to its members grants for programme development as a way of providing operation funds.

In Mali, URTEL DU MALI established in 1992 is the umbrella body for about 200 radio stations. According to Zakaria (2010), "as long as there is no clear legal umbrella, freedom of the press will not be guaranteed. Also, as long as there is no freedom of the press, access will be a problem, and good governance will remain a democratic living dream" (...). Even with the passage of the Freedom of Information (FOI) Bill in Nigeria, is there a total freedom for the nation's press? According to Sahara Reporter (2019), in the ranking of 180 countries that suppress press freedom conducted by Reporters Sans Frontières (RSF), Nigeria is ranked 120. RSF (2019) states that in Nigeria, “...covering stories involving politics, terrorism or financial embezzlement by the powerful proves problematic. Journalists are often 
threatened, subjected to physical violence or denied access to information by government officials, police...." Although much has been said on government's licensing, regulatory and control functions of community radio, there ought to be a framework put together that will allow for the establishment and management of broadcast stations by communities for their own development. For example, the community radio centre in Timor-Leste (a small country in Asia, formerly part of Indonesia) functions as a focal point for a number of supportive services for community radios in the country. In order to have community radio that is geared towards grassroots development, government needs to eliminate the outrageously prohibitive licensing fee that is delaying the proper take-off of the medium in Nigeria. This is because no rural community in the country has the financial capability to set-up such a station, except multinationals and international non-governmental agencies operating in rural communities are encouraged to help establish community radio in these areas. Therefore, it is important for advocates of community radio; rural communities based nongovernmental agencies and other developmental agencies to rouse government interest by pressuring, lobbying and pushing bills that could morph into acts or laws that will foster grassroots radio communication owned and operated by the people of the area.

\section{References}

Ajibade, O. \& Alabi, S. (2017). Community radio in Nigeria: Issues and challenges. Covenant Journal of Communication, 4(1), 2638.

Akingbulu, A. (2009). Advocacy strategies and approaches for community radio development in Nigeria. Retrieved 20 August 2019, from http://www.apc.org.

Al-hassan, S. et al. (2011). The role of community radio in livelihood improvement: The case of Simli radio. Journal of Field Actions, $5,1-6$.

Bazlur, R. A. H. M. (2009). The role of community radio in establishing good governance through right to information. Retrieved 20 August 2019, from http://www.km4dev.org

Boloka, M. (n.d). Development of community radio in South Africa. Retrieved 20 August 2019, from http://www.satya graha.org.za.

F.A.O. (1999). Voice for change: Rural women and communication. Retrieved 6 June 2019, from http://www.fao.org/docrep/ X2550E/X2550e04.htm.

FGN. (1999). Nigerian constitution. Abuja: FGN. 
Jayaweera, W. (2009). Foreword. In R. Mainali, Y. Chapagain \& B. Subba (Eds.), Community radio: Performance assessment system (pp.2-3). Kathmandu: CRSC/NEFEJ.

Julius-Adeoye, R.J. (2011). Governance, management and sustainability of community radio stations. In S.A. Shaibu \& S.K.O. Idebi (Eds.), Community radio project in Nigeria: Blueprint for national development (pp. 69-88). Ibadan: Footprints Publishers.

Kawu, I.M. (2008). The radio revolution in Mali. In A. Akingbulu (Ed.), Rooting for community radio in Nigeria (pp.29-34). Lagos: Institute for Media and Society and Panos Institute West Africa.

Mahmud, A.S. (2006). The role of community radio central to development. A paper presented at the rountable conference on community radio held in Dhaka on 15 March 2006. Retrieved 5 June 2019, from http://bangladeshictpolicy. bytesforall.net.

Mainali, R., Chapagain, Y. \& Subba, B. (2009). Community radio: Performance assessment system. Kathmandu: CRSC/NEFEJ.

Nigerian Broadcasting Corporation (n.d). Retrieved from http:// www.nbc.gov.ng/licensing.php\#

Obeng, S.K. (2010). The impact of community radio on the lives of people of sub-urban areas of Ghana. Retrieved 17 July 2019, from http://www.modernghana.com.

Omoera, O.S. (2010). The import of the media in an emerging democracy: An evaluation of the Nigerian situation. Journal of Social Sciences, 22(1), 33-38.

Omoera, O.S. (2006). Community radio in Africa: An imperative for grassroots development. Iroro: A Journal of Arts, 11(1\&2), 256-263.

Reporters Without Borders (2019). Climate of permanent violence. Retrieved 10 September 2019, from rsf.org/en/Nigeria.

Sahara Reporters. (2019). Nigeria drops in world press freedom ranking. Retrieved 16 July 2019, from http:// saharareporters.com/2019/04/20/nigeria-drops-world-pressfreedom-ranking.

Sanders, B. J., \& Goddard, C. (2002). The role of mass media in facilitating community education and child abuse prevention strategies. In Child Abuse Prevention Issues, No. 16 Winter. Melbourne: Australia Institute for Family Studies.

Uka, U.N. (2017). Health meets entertainment. Retrieved 2 September 2019, from http://www.sfhnigeria.org/3625/.

UNESCO. (2012). Women radio broadcasters in Nicaragua speak out against sexism. Retrieved 31 August 2019, from http:// www.unesco.org/.

Zakaria, N. (2010). Role of media and good governance. Retrieved 31 August 2019, from http://www.aibd.org. 